\title{
PERSONALITY TRAITS SHOW DIFFERENTIAL RELATIONS WITH ANXIETY AND DEPRESSION IN A NONCLINICAL SAMPLE
}

\author{
Yusuke TAKAHASHI'), Brent W. ROBERTS ${ }^{2)}$, Shinji YAMAGATA ${ }^{\text {(), }}$, and Nobuhiko KIJIMA ${ }^{4)}$ \\ ${ }^{1)}$ Kyoto University, Japan \\ ${ }^{2)}$ University of Illinois at Urbana-Champaign, U.S. A \\ ${ }^{3)}$ Kyushu University, Japan \\ ${ }^{4)}$ Keio University, Japan
}

\begin{abstract}
This study examined how the personality traits of behavioral inhibition and behavioral activation contribute to the development of anxiety and depression. We used two-wave short-term longitudinal data from 319 students. Data collections were two months apart. Personality traits were assessed using Gray's Reinforcement Sensitivity Theory: Behavioral Inhibition and Activation Systems (BIS and BAS). After confirming simple correlations, hierarchical regressions were conducted to test how residual changes or unique variances in psychopathology were predicted by the personality traits. Findings revealed that high BIS sensitivity predicted both anxiety and depression, while low BAS sensitivity predicted only depression. These results suggest that hyperactive BIS functions as a predictor for general distress, and that hypoactive BAS functions as a unique predictor for depression.
\end{abstract}

Key words: BIS, BAS, anxiety, depression, comorbidity, distinctiveness

\section{Introduction}

Anxiety and depression have a relatively high correlation and strong comorbidity (Kessler, Chiu, Demler, \& Walters, 2005). In clinical settings, many individuals have both anxiety symptoms and depressive symptoms. In non-clinical settings, prior research shows considerable overlap between anxiety and depression as measured by self-report questionnaires. This overlap is thought to be partially related to a lack of discriminant validity of the commonly used self-report measures (Anderson \& Hope, 2008). Item overlap may lead to artificially high correlations between anxiety and depression. However, previous study using well established scales has shown that the two constructs of anxiety and depression have some shared variance, and despite the fact that anxiety and depression are distinct constructs, they are also correlated (Muris, Schmidt, Merckelbach, \& Schouten, 2001).

The comorbidity of anxiety and depression is associated with more serious and prolonged mental health problems, which becomes a psychological, social, and clinical issue (Aina \& Susman, 2006). How can anxiety and depression be distinguished? What explains the shared variance and the non-shared variance? Perhaps the answer to these questions can be found in personality traits as an underlying contributor to anxiety and

Correspondence concerning this article should be addressed to Yusuke Takahashi, Ph.D., Graduate School of Education, Kyoto University, Yoshida Honmachi, Sakyo-ku, Kyoto 606-8501, Japan (e-mail: takahashi. yusuke.3n@kyoto-u.ac.jp). 
depression. Personality traits are a bio-psycho-social system leading to a variety of human behaviors and individual differences (Roberts \& Jackson, 2008). The dimensional model of the relationship between personality and psychopathology posits that personality traits and psychopathology lie on continua such that the relationship among them is dimensional (Tackett, 2006; Widiger \& Smith, 2008). In some cases, personality traits are associated with extreme tendencies, namely psychopathologies (Kotov, Gamez, Schmidt, \& Watson, 2010).

To elucidate the relationship between personality and anxiety/depression, in the present study we focused on Gray's biologically-based model of personality, now called the Reinforcement Sensitivity Theory (RST; Gray, 1970, 1982, 1987; Gray \& McNaughton, 2000). Gray proposed that the basis of personality consists of three major neurobehavioral motivational systems: the behavioral inhibition system (BIS), the fight-flight-freeze system (FFFS $)^{1}$, and the behavioral activation system (BAS).

The BAS was defined as a motivational system related to sensitivity to unconditioned reward signals, relief from punishment, and non-punishment (Gray, 1994). In response to these appetitive stimuli, the BAS functions to organize approach behaviors (e.g., rewardseeking, goal-directed activity), and activation of positive feelings (e.g., desire for reward, elation). Individual differences in this system are considered to underlie individual differences in trait impulsivity. The (original) BIS was defined as a motivational system related to sensitivity to punishment signals. In response to the source of conflicting stimuli, the BIS functions to organize an interruption of any ongoing behavior (i.e., behavioral inhibition) to increase the level of attention and arousal, and to activate negative feelings (e.g., anxiety, worry). Individual differences in the BIS are considered to underlie individual differences in trait anxiety.

\footnotetext{
${ }^{1}$ Gray and McNaughton (2000) revised the RST as part of an ongoing evaluation of both old and new animal-based data concerning the neuropsychology of anxiety (Smillie, Pickering, \& Jackson, 2006). The major point of Gray and McNaughton's revision relates to making a clearer distinction between anxiety and fear. Although anxiety was supposed to be a result of the BIS activation, and fear a result of FFFS activation, the findings revealed that the BIS had subsumed both phenomena (Smillie et al., 2006). The FFFS is responsible for mediating reactions to both conditioned and unconditioned aversive stimuli (Corr, 2004; Gray $\&$ McNaughton, 2000). It involves the punishment system that was a feature of the original (not revised) BIS. In response to all types of aversive stimuli, the FFFS functions to organize avoidance and escape behaviors and to activate negative feedback designed to reduce the discrepancy between the immediate threat and the desired state. Individual differences in the reactivity of the FFFS account for individual predispositions toward fear-proneness and avoidance. Indeed, recent studies reported that the factor structure of the Carver and White's (1994) BIS scale could be separated into BIS and FFFS subscales (e.g., Heym, Ferguson, \& Lawrence, 2008). However, because the BIS scale and the FFFS scale are highly correlated with each other, it is not clear yet whether both BIS and FFFS play much the same role for developing anxiety and depression. As White and Depue (1999) stated, the fact that they have been treated as equivalent constructs in the wider psychology literature may make it difficult to distinguish between fear and anxiety. In fact, the symptoms of panic disorder and anxiety disorder show a similar overlap in clinical settings (Gray \& McNaughton, 2000; Smillie et al., 2006). Although Corr and McNaughton (2008) and Poythress et al. (2008) discussed the need for future research to distinguish between the FFFS (fear) and the BIS (anxiety), Corr (2004) also suggested that the BIS functioning was originally studied as combined BIS/FFFS functioning. Therefore, in this article we refer to BIS/FFFS functioning as the BIS functioning, and we focus only on the BIS (sensitivity to punishment) and the BAS (sensitivity to reward) as the key personality structures.
} 
One of the big appeals of the RST is that it assumes biologically-based underpinnings of personality: BIS involves the septo-hippocampal system and the brain stem, and also BAS involves dopaminergic pathways in the brain (Gray, 1990; McNaughton \& Corr, 2004; Smillie, 2008). Another strength of the RST is the significant association with various psychopathologies. Since the RST originally assumed that individuals with high or low level of BIS and BAS are at increased risk for developing psychopathology (Bijttebier, Beck, Claes, \& Vandereycken, 2009; Pickering \& Gray, 1999), it is of researchers' primary interest as to how BIS and BAS can predict and explain specific psychopathologies. In fact, Bijttebier et al. (2009) reviewed the relationship between the BIS, the BAS, and various psychopathologies. To be taken into account the above two strengths of RST, we can find that the personality dimensions of RST function as trait markers, trait vulnerabilities, and endophenotypes (Gottesman \& Gould, 2003) for psychopathology.

As shown in Table 1, with regard to links between anxiety/depression and personality traits, several studies reported that high BIS sensitivity is associated with both depression and anxiety, and that low BAS sensitivity is associated with only depression (e.g., Beevers \& Meyer, 2002; Campbell-Sills, Liverant, \& Brown, 2004; Hundt, Nelson-Gray, Kimbrel, Mitchell, \& Kwapil, 2007; Kimbrel, Nelson-Gray, \& Mitchell, 2007; Segarra et al., 2007). These studies indicate that an elevated BIS links to comorbidity of anxiety and depression, whereas a weak BAS functions as a distinct factor of depression. However, other studies showed that the BIS is positively correlated with both depression and anxiety, and that the BAS has no significant association with either symptom (Johnson, Turner, \& Iwata, 2003; Jorm et al., 1999; Muris, Meesters, De Kanter, \& Timmerman, 2005). Moreover, Coplan, Wilson, Frohlick, and Zelenski (2006) showed that both anxiety and depression are characterized by high BIS and low BAS.

Table 1. Relations between BIS/BAS and anxiety/depression

\begin{tabular}{|c|c|c|c|c|c|}
\hline \multirow{2}{*}{ authors } & \multicolumn{2}{|c|}{ anxiety } & \multicolumn{2}{|c|}{ depression } & \multirow{2}{*}{ what sample? } \\
\hline & BIS & BAS & BIS & BAS & \\
\hline Johnson et al. (2003) & + & n.s. & + & n.s. & community \\
\hline Jorm et al. (1999) & + & n.s. & + & n.s. & community \\
\hline Muris et al. (2005) & + & n.s. & + & n.s. & community \\
\hline Beevers \& Meyer (2002) & + & n.s. & + & - & student \\
\hline Campbell-Sills et al. (2004) & + & n.s. & + & - & clinical \\
\hline Kimbrel et al. (2007) & + & n.s. & + & - & community \\
\hline Hundt et al. (2007) & + & n.s. & + & - & student \\
\hline Segarra et al. (2007) & + & n.s. & + & - & student \\
\hline Coplan et al. (2006) & + & - & + & - & community \\
\hline
\end{tabular}

Note. + : positive correlations, -: negative correlations. 
Taken together, empirical evidence shows that BIS hyperactivity is consistently related to both anxiety and depression, and is a common vulnerability factor (Table 1). In contrast, the links between BAS hypoactivity, anxiety and depression are less consistent (Table 1). One possible reason for the inconsistent results is that almost all of these studies are cross-sectional and therefore the patterns of correlations may be confounded by current mood or circumstances.

\section{The purpose of this study}

The main purpose of the present study was to use a short-term longitudinal design to control for cross-sectional confounds when examining the relations among BIS, BAS, anxiety, and depression. Specifically, in the present study, we sought to control two types of confounds: (a) comorbidity (i.e., collinearity between anxiety and depression) and (b) initial level (this includes a kind of state effect). Comorbidity undermines the ability to distinguish the roles BIS and BAS play in predicting anxiety and depression. For example, the relation of BAS to depression may simply be the result of the shared variance of depression with anxiety. Presumably, if this were the case, then this pattern would disappear if we controlled for the comorbid factor of anxiety. Controlling for the initial levels of anxiety and depression in a short-term longitudinal design effectively controls for current mood or psychopathology. Thus, we focused on the research question: how do BIS and BAS predict anxiety and depression at Time 2, controlling for Time 1 levels of anxiety and depression (respectively)? To test this idea, we conducted a hierarchical regression analysis in terms of how a unique depression component that partialled out anxiety or a unique anxiety component that partialled out depression is predicted by personality traits. Controlling for the above two confounds should clarify the relationship between BIS and BAS traits and the two internalizing psychopathologies of anxiety and depression.

\section{METHOD}

\section{Participants}

The participants were Japanese undergraduate students taking an introductory psychology course. Informed consent was obtained before administration of the pen and paper questionnaires. The students spent about 30 minutes filling out the questionnaires in exchange for extra course credit. This study was designed as a two-wave short-term longitudinal survey; the interval between Time 1 and Time 2 was two months. The questionnaire at Time 1 included the personality trait scales and the anxiety and depressive symptoms scales, whereas the questionnaire at Time 2 had the anxiety and depressive symptoms scales only. A total of 319 undergraduate students (219 female and 100 male) completed the questionnaires at both Time 1 and Time 2; they ranged in age between 18 to 23 years old $(M=18.77, S D=.81$ years). Although our sample had no attrition between Times 1 and 2, when observations contained missing values, pairwise deletion was used.

\section{Questionnaires}

Personality traits were measured by the BIS and BAS Scale (Carver \& White, 1994; Takahashi et al., 2007). This scale is one of the most widely used self-report measures of personality traits based on Gray's Reinforcement Sensitivity Theory (RST). It consists of 20 items that measure individual differences in the sensitivity of the behavioral inhibition system (BIS; 7 items; e.g., "I worry about making mistakes") and the behavioral activation system (BAS; 13 items; e.g., "I crave excitement and new sensations"). Participants were asked to describe themselves using a 4-point Likert scale $(1=$ "very false for me" to $4=$ "very true for 
me") to assess four subscales: BIS, BAS fun seeking, BAS reward responsiveness, and BAS drive. In the present study, the last three subscales added together were used to determine the overall level of BAS sensitivity. This scale has well-established psychometric properties and has shown good reliability and validity with a variety of populations (Carver \& White, 1994; Leone, Perugini, Bagozzi, Pierro, \& Mannetti, 2001; Takahashi et al., 2007). For the present sample, Cronbach's alpha coefficients for this scale were .81 for BIS and .79 for BAS.

Anxiety symptoms were measured by the State-Trait Anxiety Inventory: A-State (STAI-S; Shimizu \& Imae, 1981; Spielberger, Gorsuch, \& Lushene, 1970). Participants were asked to evaluate how anxious they felt at a particular time in the recent past using 20 items (e.g., "I feel secure" [reversed]) with 4-point Likert scales ( $1=$ "not at all" to $4=$ "very much so"). Higher scores represent greater state anxiety in general. The STAI-S is a widely used measure with adequate psychometric properties. For the present sample, Cronbach's alpha coefficients for the STAI-S were .90 for Time 1, and .92 for Time 2 .

Depressive symptoms were assessed by the Zung's Self-rating Depression Scale (SDS; Fukuda \& Kobayashi, 1973; Zung, 1965). This scale measures temporary depressive symptoms using 20 items (e.g., "I feel down-hearted and blue") rated on a 4-point Likert scale ( $1=$ "a little of the time" to $4=$ "most of the time"). Higher scores represent greater depressive symptoms in general. The SDS has demonstrated good psychometric properties, including satisfactory short-term test-retest reliability and internal consistency. For the present sample, Cronbach's alpha coefficients for the SDS were .81 for Time 1, and .80 for Time 2 .

\section{RESULTS}

The results are presented in two main sections after the preliminary analyses. First, we focused on the question of how personality traits at Time 1 contributed to the unique component in internalizing psychopathologies of anxiety and depression after controlling for comorbidity. We next investigated how personality traits could predict residual changes on internalizing psychopathologies of anxiety and depression from Time 1 to Time 2, controlling for the initial levels of anxiety and depression.

\section{Descriptive statistics and preliminary analyses}

Means, standard deviations, and score ranges were calculated for each scale (see the left half of Table 2). Inter-correlations between scales were also computed (see the right

Table 2. Means, standard deviations, and inter-correlations between the variables in this study

\begin{tabular}{|c|c|c|c|c|c|c|c|c|c|c|}
\hline & \multirow[b]{2}{*}{$M$} & \multirow[b]{2}{*}{$S D$} & \multirow[b]{2}{*}{$\begin{array}{l}\text { score } \\
\text { range }\end{array}$} & \multirow[b]{2}{*}{$\min$} & \multirow[b]{2}{*}{$\max$} & \multicolumn{5}{|c|}{ correlations } \\
\hline & & & & & & BIS & BAS & $\begin{array}{c}\text { anxiety } \\
\text { (T1) }\end{array}$ & $\begin{array}{c}\text { anxiety } \\
\text { (T2) }\end{array}$ & $\begin{array}{l}\text { depression } \\
\text { (T1) }\end{array}$ \\
\hline BIS & 21.35 & 4.17 & $7-28$ & 7 & 28 & - & & & & \\
\hline BAS & 41.40 & 5.45 & $13-52$ & 16 & 52 & $.11^{*}$ & - & & & \\
\hline anxiety (T1) & 41.88 & 10.28 & $20-80$ & 20 & 80 & $.38^{*}$ & .00 & - & & \\
\hline anxiety (T2) & 43.55 & 10.61 & $20-80$ & 20 & 77 & $.32 *$ & .04 & $.56^{*}$ & - & \\
\hline depression (T1) & 42.20 & 8.47 & $20-80$ & 22 & 80 & $.35^{*}$ & -.07 & $.69^{*}$ & $.52 *$ & - \\
\hline depression (T2) & 42.93 & 8.69 & $20-80$ & 21 & 79 & $.35^{*}$ & -.10 & $.54 *$ & $.64 *$ & $.70^{*}$ \\
\hline
\end{tabular}

Note: T1: Time 1, and T2: Time 2. ${ }^{*} p<.05$. 
half of Table 2). The correlation matrix revealed that higher BIS scores were related to higher anxiety and depressive symptoms in all cases, and that BAS scores were not significantly related to these symptoms. Anxiety was positively correlated with depression, indicating that anxiety and depression were strongly comorbid with each other at both measurement times. Moreover, we observed that each internalizing psychopathology score of anxiety or depression at Time 1 was correlated with the score at Time 2 . These correlation coefficients appear high, but in terms of the proportion of the explained variance, in the two months between Time 1 and 2, 69\% of the variance for anxiety and 51\% of the variance for depression changed (i.e., were unexplained by the score at Time 1).

\section{Hierarchical regression analyses: Controlling for comorbidity}

Hierarchical regression analyses were conducted to explain the unique variances of each internalizing psychopathology of anxiety or depression after controlling for comorbidity. At the first step, the demographic variables were entered into a regression formula to partial out their variances. Next, at the second step of the regression, to control the comorbidity of anxiety and depressive symptoms, anxiety or depressive symptom scores at Time 2 were each entered as a covariate (i.e., in the regression formula on anxiety, depression was entered as a covariate, and vice versa). After partialling the demographic variables and covariates, at the third and final step, the BIS and BAS scores were entered to examine their predictive power for the variances of the internalizing psychopathologies. The results of these hierarchical regressions are shown in Table 3. As shown in that table, we found that anxiety was significantly predicted by higher BIS, and depression was significantly predicted by higher BIS and lower BAS.

\section{Hierarchical regression analyses: controlling for initial levels at Time 1}

To examine how the changes of the internalizing psychopathologies of anxiety and depression from Time 1 to Time 2 were explained by personality traits, we first entered the demographic variables (i.e., age and sex) into a regression formula. After that, we entered the anxiety or depressive symptoms scores at Time 1 as a covariate to control for the initial level at the second step. Then the set of personality traits (i.e., BIS and BAS) were entered as independent variables at the third and final step. The results of these hierarchical regressions are shown in Table 3. The results indicated that after partialling the demographic variables and the score at Time 1, anxiety symptoms were significantly predicted by higher BIS, and depressive symptoms were significantly predicted by higher BIS and lower BAS.

\section{DISCUSSION}

The overall purpose of the present short-term longitudinal study was to examine whether personality traits differentially influence anxiety and depression, which themselves are highly correlated, and to distinctively describe the characteristics of these two internalizing psychopathologies of anxiety and depression.

First, the results of simple correlation analyses revealed that we replicated high 
Table 3. Results of hierarchical regression analyses predicting change or unique variance in anxiety or depression

\begin{tabular}{|c|c|c|c|c|c|c|c|}
\hline \multicolumn{2}{|c|}{ steps } & $R^{2}$ & $\Delta R^{2}$ & $F$ & $d f$ & $\beta$ & $\begin{array}{c}t \\
\text { within step }\end{array}$ \\
\hline \multicolumn{8}{|c|}{ predicting unique variance in anxiety } \\
\hline \multirow[t]{3}{*}{1} & demographic variables & .00 & & .25 & $(2,297)$ & & \\
\hline & $\operatorname{sex}$ & & & & & .03 & .49 \\
\hline & age & & & & & .03 & .47 \\
\hline \multirow[t]{2}{*}{2} & covariates & .40 & .40 & $195.83 *$ & $(1,296)$ & & \\
\hline & depression (T2) & & & & & .63 & $13.99 *$ \\
\hline \multirow[t]{3}{*}{3} & personality traits & .42 & .02 & $5.07 *$ & $(2,294)$ & & \\
\hline & BIS & & & & & .12 & $2.53 *$ \\
\hline & BAS & & & & & .07 & 1.54 \\
\hline \multicolumn{8}{|c|}{ predicting unique variance in depression } \\
\hline \multirow[t]{3}{*}{1} & demographic variables & .00 & & .71 & $(2,297)$ & & \\
\hline & $\operatorname{sex}$ & & & & & -.07 & -1.12 \\
\hline & age & & & & & -.02 & -.33 \\
\hline \multirow[t]{2}{*}{2} & covariates & .40 & .40 & $195.83 *$ & $(1,296)$ & & \\
\hline & anxiety (T2) & & & & & .63 & $13.99 *$ \\
\hline \multirow[t]{3}{*}{3} & personality traits & .43 & .03 & $8.54 *$ & $(2,294)$ & & \\
\hline & BIS & & & & & .16 & $3.41^{*}$ \\
\hline & BAS & & & & & -.12 & $-2.69 *$ \\
\hline \multicolumn{8}{|c|}{ predicting change in anxiety } \\
\hline \multirow[t]{3}{*}{1} & demographic variables & .00 & & .25 & $(2,297)$ & & \\
\hline & $\operatorname{sex}$ & & & & & .03 & .49 \\
\hline & age & & & & & .03 & .47 \\
\hline \multirow[t]{2}{*}{2} & covariates & .31 & .31 & $130.95 *$ & $(1,296)$ & & \\
\hline & anxiety (T1) & & & & & .56 & $11.44^{*}$ \\
\hline \multirow[t]{3}{*}{3} & personality traits & .32 & .01 & $3.32 *$ & $(2,294)$ & & \\
\hline & BIS & & & & & .13 & $2.46^{*}$ \\
\hline & BAS & & & & & .02 & .45 \\
\hline \multicolumn{8}{|c|}{ predicting change in depression } \\
\hline \multirow[t]{3}{*}{1} & demographic variables & .01 & & .72 & $(2,300)$ & & \\
\hline & $\operatorname{sex}$ & & & & & -.07 & -1.12 \\
\hline & age & & & & & -.02 & -.33 \\
\hline \multirow[t]{2}{*}{2} & covariates & .52 & .51 & $323.45^{*}$ & $(1,299)$ & & \\
\hline & depression (T1) & & & & & .72 & $17.99 *$ \\
\hline \multirow[t]{3}{*}{3} & personality traits & .55 & .03 & $7.11 *$ & $(2,297)$ & & \\
\hline & BIS & & & & & .11 & $2.49^{*}$ \\
\hline & BAS & & & & & -.13 & $-2.78 *$ \\
\hline
\end{tabular}

Note:* $p<.05$. 
correlations between anxiety and depression. Additionally, the results showed that anxiety was significantly and positively associated with BIS. Depression was also significantly and positively associated with BIS, and was not associated with BAS. This finding of no significant correlational relationship between depression and BAS suggests a replication of the prior research (Johnson et al., 2003; Jorm et al., 1999; Muris et al., 2005). However, as mentioned in the Introduction, a negative correlation between depression and BAS has been found inconsistently in past research.

Instead of relying on simple cross-sectional correlations, we used a short-term longitudinal design to provide a more stringent test of the unique contribution of BIS and BAS to both anxiety and depression. With regard to the relationship between BIS and BAS and anxiety, we found results in the first hierarchical regression analysis in which the comorbid variance attributable to depression was controlled for. Furthermore, the second hierarchical regression analysis controlled for the initial level of anxiety at Time 1 . We found that BIS significantly predicted residual changes in anxiety. This suggests that high BIS sensitivity is uniquely linked to higher anxiety.

With respect to depression and the BIS and BAS personality traits, when controlling for anxiety levels, BIS and BAS both predicted depression at Time 2. Furthermore, the second hierarchical regression analysis which controlled for the initial level of depression revealed that residual changes in depressive symptoms were significantly predicted by both BIS and BAS at Time 1. These results are consistent with the simple correlations between BIS and depressive symptoms. On the other hand, simple correlations between BAS and depressive symptoms were not significant, but the results of these hierarchical regression analyses, which can control for potential confounds, show that BAS is linked to depression when either comorbid confounds or initial level are controlled.

The results from this study are fairly robust in showing that higher BIS was a significant predictor for anxiety and depression. Being overly vigilant (which reflects a tendency to be sensitive to signals of punishments, frustration at the prospect of nonrewards, and fear of novel stimuli) results in vulnerability for internalizing psychopathologies. What about the link between BAS and depression? In the present study we observed no significant simple correlations, and previous studies showed mixed results. However, the regression models here suggest that hypoactivity of BAS can play an important role as a trait marker for only depression, not anxiety (Hundt et al., 2007; Kimbrel et al., 2007; Segarra et al., 2007); this was originally proposed by Gray $(1987,1991)$. We provided evidence that a negligible (i.e., statistically non-significant) simple correlation could be transformed into a significant link when relevant confounds were considered (Watson, Clark, Chmielewski, \& Kotov, 2013). Future research linking BIS and BAS to internalizing psychopathology might reveal more consistent evidence for BAS if similar strategies are more widely employed. However, this study could not answer the question which one was a specific reason for inconsistent results of previous studies, comorbidity and/or initial level (state effect). Although comorbidity was thought to be the first candidate to be responsible for mixed results, our findings revealed that controlling for initial level also made clearer the links between BIS/BAS and anxiety/depression. This means that when using longitudinal dataset, if any of two types of confounds was partialled out, the results 
are more likely to be consistent. Future research is needed to determine which confounds more specifically contribute to the inconsistent results of previous studies.

Again, at least, in the findings of the present study, BIS was a shared predictor of both anxiety and depression. This implies that BIS may be one of the factors for the comorbidity of anxiety and depression since they both derive from the same personality trait. In contrast, BAS was a unique predictor for depression. The results suggest that hypoactive BAS is more likely to be a factor helping to differentiate between the internalizing psychopathologies of anxiety and depression. The RST originally assumed that the BAS represents a motivation mechanism related to the reward system, and BAS may be associated with the dopaminergic pathways (mesolimbic and nigrostriatal pathways; Gray, 1994; Schultz, 2006). Our findings suggest a possible route from low BAS to a mechanism for depression. If the reward-related processing function in the human brain is weakened, this would lead to a hypoactive BAS; reward-seeking behavior would be lower, and the person would manifest depressive mood. Takahashi, Ozaki, Roberts, and Ando (2012) demonstrated that the model's assumption of unidirectional paths from BAS to depressive mood were consistently supported, using non-normal structural equation modeling, which suggests that reduced BAS activity is a precursor to the development of depressive mood. Moreover, previous research has revealed a relationship between dopamine levels and depression from a clinical perspective (Rampello, Nicoletti, \& Nicoletti, 2000). Future research could investigate low sensitivity to reward among highly depressed individuals, and to the relationship between depression and the BAS, which is associated with the reward-related processing function. Taken together, our findings may have several clinical implications which remain largely speculative. Assessing personality traits using BIS and BAS of personality traits could contribute to (a) the improvement in diagnostic accuracy of anxiety and depression, (b) choosing more appropriate medication in pharmaceutical therapy settings, and (c) discussing treatment options in cognitive behavioral therapy and other psychosocial approaches.

Further research is needed as the present study is not without limitations. First, this study was conducted within a short time period. To confirm the predictive effects of personality traits on the development of anxiety and depressive symptoms, a longitudinal study which has a longer time period is needed. In fact, several previous studies suggest that personality traits have a longer-term predictive validity for a variety of psychopathologies (Caspi, 2000; Krueger, 1999; Ozer \& Benet-Martínez, 2006; Tackett, 2006). Second, the study sample was only non-clinical college students, which may limit generalizing the findings to clinical samples and other age groups. However, using clinical samples may pose their own difficulties, because clinical samples may already be on medications that act on BAS sensitivity. This may be another reason for the inconsistent results about the relationship between BAS and major depression. Third, in this study, $68.7 \%$ of participants were female. Because the gender bias was observed, the effect of gender was controlled in the regression equations. However, because previous research found that there were significant gender differences in both anxiety and depression across the adult lifespan (Leach, Christensen, Mackinnon, Windsor, \& Butterworth, 2008), further investigation is needed to clarify the gender differences. Forth, the scales used in this study had some item 
overlaps. To describe the distinctive features between anxiety and depression more clearly, using scales designed to assess specific symptom dimensions related to anxiety and depression should be considered (Watson et al., 2007). Fifth and finally, when covariates which were highly correlated with the dependent variables were thrown into the regression model, the incremental explained variance was often relatively small, around $1 \%$ to $3 \%$ although, these values were statistically significant. We do not think that only BIS and BAS adequately explain the developmental mechanism of anxiety and depression. A diathesis-stress model which includes an interaction term and a mediation model need to be explored further (e.g., Beevers \& Meyer, 2002).

Despite these limitations, our findings support and extend prior research on the effects of personality traits on internalizing psychopathologies. There was relatively little research examining the overlap and distinctiveness between anxiety and depression simultaneously, systematically, and longitudinally. The present research sheds some light on this from the viewpoint of BIS and BAS traits, indicating that BIS could be a factor in the overlap, and BAS may contribute to distinctiveness. Although there is controversy as to whether a certain personality trait is uniquely related to certain psychopathological tendencies, clearly describing personality traits as precedent factors, such as in the present study, often leads to enhancing our knowledge about precursors related to psychopathologies.

\section{REFERENCES}

Aina, Y., \& Susman, J. L. 2006. Understanding comorbidity with depression and anxiety disorders. Journal of the American Osteopathic Association, 106(Suppl. 2), S9-S14.

Anderson, E. R., \& Hope, D. A. 2008. A review of the tripartite model for understanding the link between anxiety and depression in youth. Clinical Psychology Review, 28, 275-287.

Beevers, C. G., \& Meyer, B. 2002. Lack of positive experiences and positive expectancies mediate the relationship between BAS responsiveness and depression. Cognition and Emotion, 16, 549-564.

Bijttebier, P., Beck, I., Claes, L, \& Vandereycken, W. 2009. Gray's Reinforcement Sensitivity Theory as a framework for research on personality-psychopathology associations. Clinical Psychology Review, 29, 421-430.

Campbell-Sills, L., Liverant, G. I., \& Brown, T. A. 2004. Psychometric evaluation of the Behavioral Inhibition/ Behavioral Activation scales in a large sample of outpatients with anxiety and mood disorders. Psychological Assessment, 16, 244-254.

Carver, C. S., \& White, T. L. 1994. Behavioral inhibition, behavioral activation, and affective responses to impending reward and punishment: The BIS/BAS scales. Journal of Personality and Social Psychology, 67, 319-333.

Caspi, A. 2000. The child is father of the man: Personality continuities from childhood to adulthood. Journal of Personality and Social Psychology, 78, 158-172.

Coplan, R. J., Wilson, J., Frohlick, S. L., \& Zelenski, J. 2006. A person-oriented analysis of behavioral inhibition and behavioral activation in children. Personality and Individual Differences, 41, 917-927.

Corr, P. J. 2004. Reinforcement sensitivity theory and personality. Neuroscience and Biobehavioral Reviews, 28, 317-332.

Corr, P. J., \& McNaughton, N. 2008. Reinforcement sensitivity theory and personality. In P. J. Corr (Ed)., The reinforcement sensitivity theory of personality (pp. 155-187). Cambridge, United Kingdom: Cambridge University Press.

Fukuda, K., \& Kobayashi, S. 1973. A study on a self-rating depression scale. Psychiatria et Nuerologia Japonica, 75, 673-679. (In Japanese)

Gottesman, I. I., \& Gould, T. D. 2003. The endophenotype concept in psychiatry: Etymology and strategic 
intentions. American Journal of Psychiatry, 160, 636-645.

Gray, J. A. 1970. The psychophysiological basis of introversion-extraversion. Behaviour Research and Therapy, 8, 249-266.

Gray, J. A. 1982. Neuropsychological theory of anxiety. New York, NY: Oxford University Press.

Gray, J. A. 1987. The psychology of fear and stress. Cambridge, United Kingdom: Cambridge University Press.

Gray, J. A. 1990. Brain systems that mediate both emotion and cognition. Cognition and Emotion, 4, 269288.

Gray, J. A. 1991. The neuropsychology of temperament. In J. Strelau \& A. Angleitner (Eds.), Explorations in temperament: International perspectives on theory and measurement (pp. 105-128). New York, NY: Plenum Press.

Gray, J. A. 1994. Framework for a taxonomy of psychiatric disorder. In S. H. M. van Goozen, N. E. van de Poll, \& J. Sergeant (Eds.), Emotions: Essays on emotion theory (pp. 29-59). Hillsdale, NJ: Erlbaum.

Gray, J. A., \& McNaughton, N. 2000. The neuropsychology of anxiety (2nd ed.). New York, NY: Oxford University Press.

Heym, N., Ferguson, E., \& Lawrence, C. 2008. An evaluation of the relationship between Gray's revised RST and Eysenck's PEN: Distinguishing BIS and FFFS in Carver and White's BIS/BAS scales. Personality and Individual Differences, 45, 709-715.

Hundt, N. E., Nelson-Gray, R. O., Kimbrel, N. A., Mitchell, J. T., \& Kwapil, T. R. 2007. The interaction of reinforcement sensitivity and life events in the prediction of anhedonic depression and mixed anxietydepression symptoms. Personality and Individual Differences, 43, 1001-1012.

Johnson, S. L., Turner, R. J., \& Iwata, N. 2003. BIS/BAS levels and psychiatric disorder: An epidemiological study. Journal of Psychopathology and Behavioral Assessment, 25, 25-36.

Jorm, A. F., Christensen, H., Henderson, A. S., Jacomb, P. A., Korten, A. E., \& Rodgers, B. 1999. Using the BIS/BAS scales to measure behavioural inhibition and behavioural activation: Factor structure, validity and norms in a large community sample. Personality and Individual Differences, 26, 49-58.

Kessler, R. C., Chiu, W. T., Demler, O., \& Walters, E. E. 2005. Prevalence, severity, and comorbidity of 12-month DSM-IV disorders in the National Comorbidity Survey Replication. Archives of General Psychiatry, 62, 617-627.

Kimbrel, N. A., Nelson-Gray, R. O., \& Mitchell, J. T. 2007. Reinforcement sensitivity and maternal style as predictors of psychopathology. Personality and Individual Differences, 42, 1139-1149.

Kotov, R., Gamez, W., Schmidt, F., \& Watson, D. 2010. Linking “Big” personality traits to anxiety, depressive, and substance use disorders: A meta-analysis. Psychological Bulletin, 136, 768-821.

Krueger, R. F. 1999. Personality traits in late adolescence predict mental disorders in early adulthood: A prospective-epidemiological study. Journal of Personality, 67, 39-65.

Leach, L. S., Christensen, H., Mackinnon, A. J., Windsor, T. D., \& Butterworth, P. 2008. Gender differences in depression and anxiety across the adult lifespan: The role of psychosocial mediators. Social Psychiatry and Psychiatric Epidemiology, 43, 983-998.

Leone, L., Perugini, M., Bagozzi, R. P., Pierro, A., \& Mannetti, L. 2001. Construct validity and generalizability of the Carver-White Behavioural Inhibition System/Behavioural Activation System scales. European Journal of Personality, 15, 373-390.

McNaughton, N., \& Corr, P. J. 2004. A two-dimensional neuropsychology of defense: Fear/anxiety and defensive distance. Neuroscience and Biobehavioral Reviews, 28, 285-305.

Muris, P., Meesters, C., De Kanter, E., \& Timmerman, P. E. 2005. Behavioural inhibition and behavioural activation system scales for children: Relationships with Eysenck's personality traits and psychopathological symptoms. Personality and Individual Differences, 38, 831-841.

Muris, P., Schmidt, H., Merckelbach, H., \& Schouten, E. 2001. The structure of negative emotions in adolescents. Journal of Abnormal Child Psychology, 29, 331-337.

Ozer, D. J., \& Benet-Martínez, V. 2006. Personality and the prediction of consequential outcomes. Annual Review of Psychology, 57, 401-421.

Pickering, A. D., \& Gray, J. A. 1999. The neuroscience of personality. In L. A. Pervin \& O. P. John (Eds.), Handbook of personality (2nd ed., pp. 277-299). New York, NY: The Guilford Press.

Poythress, N. G., Skeem, J. L., Weir, J., Lilienfeld, S. O., Douglas, K. S., Edens, J. F., \& Kennealy, P. J. 2008. Psychometric properties of Carver and White's (1994) BIS/BAS scales in a large sample of offenders. 
Personality and Individual Differences, 45, 732-737.

Rampello, L., Nicoletti, F., \& Nicoletti, F. 2000. Dopamine and depression: Therapeutic implications. CNS Drugs, 13, 35-45.

Roberts, B. W., \& Jackson, J. J. 2008. Sociogenomic personality psychology. Journal of Personality, 76, $1523-1544$.

Schultz, W. 2006. Behavioral theories and the neurophysiology of reward. Annual Review of Psychology, 57, $87-115$.

Segarra, P., Ross, S. R., Pastor, M. C., Montañés, S., Poy, R., \& Moltó, J. 2007. MMPI-2 predictors of Gray’s two-factor reinforcement sensitivity theory. Personality and Individual Differences, 43, 437-448.

Shimizu, H., \& Imae, K. 1981. Development of the Japanese edition of the Spielberger State-Trait Anxiety Inventory (STAI) for student use. Japanese Journal of Educational Psychology, 29, 348-353. (In Japanese)

Smillie, L. 2008. What is reinforcement sensitivity? Neuroscience paradigms for approach-avoidance process theories of personality. European Journal of Personality, 22, 359-384.

Smillie, L. D., Pickering, A. D., \& Jackson, C. J. 2006. The new reinforcement sensitivity theory: Implications for personality measurement. Personality and Social Psychology Review, 10, 320-335.

Spielberger, C. D., Gorsuch, R. L., \& Lushene, R. E. 1970. The State-Trait Anxiety Inventory: Self evaluation questionnaire. Palo Alto, CA: Consulting Psychologist Press.

Tackett, J. L. 2006. Evaluating models of the personality-psychopathology relationship in children and adolescents. Clinical Psychology Review, 26, 584-599

Takahashi, Y., Ozaki, K., Roberts, B. W., \& Ando, J. 2012. Can low Behavioral Activation System predict depressive mood?: An application of non-normal structural equation modeling. Japanese Psychological Research, 54, 170-181.

Takahashi, Y., Yamagata, S., Kijima, N., Shigemasu, K., Ono, Y., \& Ando, J. 2007. Gray’s temperament model: Development of Japanese version of BIS/BAS scales and a behavior genetic investigation using the twin method. Japanese Journal of Personality, 15, 276-289. (In Japanese with English abstract)

Watson, D., Clark, L. A., Chmielewski, M., \& Kotov, R. 2013. The value of suppressor effects in explicating the construct validity of symptom measures. Psychological Assessment, 25, 929-941.

Watson, D., O’Hara, M. W., Simms, L. J., Kotov, R., Chmielewski, M., McDade-Montez, E. A., ... Stuart, S. 2007. Development and validation of the Inventory of Depression and Anxiety Symptoms (IDAS). Psychological Assessment, 19, 253-268.

White, T. L., \& Depue, R. A. 1999. Differential association of traits of fear and anxiety with norepinephrineand dark-induced pupil reactivity. Journal of Personality and Social Psychology, 77, 863-877.

Widiger, T. A., \& Smith, G. T. 2008. Personality and psychopathology. In O. P. John, R. W. Robins, \& L. A. Pervin (Eds.), Handbook of personality: Theory and research (3rd ed., pp. 743-769). New York, NY: Guilford Press.

Zung, W. W. K. 1965. A self-rating depression scale. Archives of General Psychiatry, 12, 63-70.

(Manuscript received 2 April, 2014; Revision accepted 23 January, 2015) 